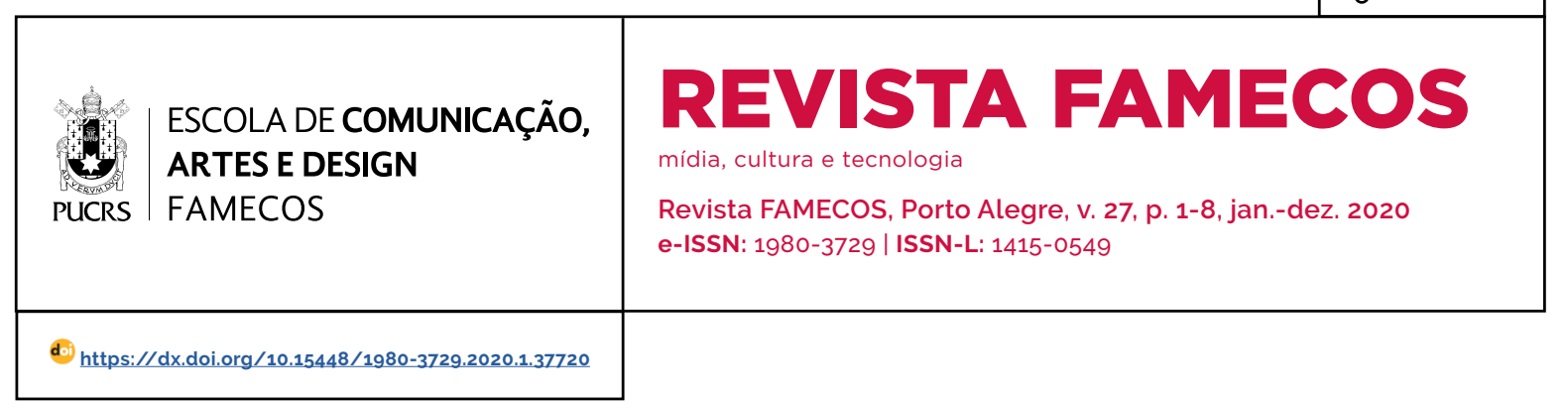

SEÇÃO: RESENHA

\title{
A arqueologia das mídias e uma nova agenda para os estudos de cinema
}

\author{
Media archeology and a new agenda for cinema studies \\ Arqueología de los medios y una nueva agenda para los estudios cinematográficos
}

\author{
Pablo Gonçalo ${ }^{1}$ \\ 0000-0002-3745-161X \\ pablogoncalo@gmail.com
}

Recebido em: 16/4/2020. Aprovado em: 17/4/2020. Publicado em: 17/12/2020.

\section{ELSAESSER, Thomas. Cinema como arqueologia das mídias. São} Paulo: Sesc Edições, 2018.

Resumo: Resenha do Livro Cinema como Arqueologia das Midias, de Thomas Elsaesser, lançado em 2018. Trata-se de uma obra importante para a atual agenda dos estudos de cinema. Com um argumento consistente. Elsaesser sugere uma compreensão do impacto da tecnologia digital no cinema a partir de uma perspectiva arqueológica, a qual possui a descontinuidade histórica como um dos seus primados. Dessa forma, o autor revisita conceitos e metodologias essenciais dos estudos de cinema, tais como dispositivo, linguagem e narrativa, origem do cinema, pesquisas com espectadores e, até mesmo, o impacto do chamado "cinema de atrações", no periodo do "primeiro cinema". A cada revisão desses conceitos, Elsaesser aponta que o estudo de descontinuidades pode gerar um profundo impacto nos estudos de cinema contemporâneos. O autor alemão também apresenta o conceito de poética da obsolescência, ressaltando cineastas e artistas visuais com projetos estéticos afins à arqueologia da mídia. Palavras-chaves: Arqueologia da midia. História do cinema. Teoria cinematográfica. Thomas Elsaesser. Genealogia.

Abstract:Review of the book Cinema as Archeology of the Media, by Thomas Elsaesser, released in 2018. This is an important work for the current agenda of cinema studies. With a consistent argument, Elsaesser suggests an understanding of the impact of digital technology on cinema from an archaeological perspective, which has on historical discontinuity one of its epitomes. Under this circumstances, the author revisits essential concepts and methodologies of cinema studies, such as device, language and narrative, cinema origins, research with audiences, viewers and even the impact of the so-called "cinema of attractions", in the "early cinema" period. While reviewing these these concepts, Elsaesser points out that the study of discontinuities may have a profound impact on contemporary film studies. The German author also presents the concept of poetics of obsoloscence, emphasizing filmmakers and visual artists with aesthetic projects akin to media archeology.

Keywords: Media archeology. Film history. Film theory. Thomas Elsaesser. Genealogy

Resumen: Reseña del libro Cinema as Archaeology of the Media, de Thomas Elsaesser, publicado en 2018. Se trata de una obra importante para la actual agenda de estudios cinematográficos. Con un argumento coherente, Elsaesser sugiere una comprensión del impacto de la tecnología digital en el cine desde una perspectiva arqueológica, que tiene la discontinuidad histórica como uno de sus primates. De esta forma, el autor revisa conceptos y metodologías esenciales de los estudios cinematográficos, como el dispositivo, el lenguaje y la narrativa, el origen del cine, la investigación con los espectadores e incluso el impacto del llamado "cine de atracciones", en la época del "primer cine". Con cada revisión 
de estos conceptos, Elsaesser señala que el estudio de las discontinuidades puede tener un profundo impacto en los estudios del cine contemporáneo. El autor alemán también presenta el concepto de poética de la obsolescencia, haciendo hincapié en cineastas y artistas visuales con proyectos estéticos relacionados con la arqueología mediática.

Palabras clave: Arqueología de los medios. Historia del cine. Teoría del cine. Thomas Elsaesser. Genealogía.

Diante da convergência digital, a história e a teoria do cinema encontraram-se em uma encruzilhada. São vários os desafios impostos, as direções e os rumos possiveis. Constantemente marcado por "mortes" e "renascimentos", o cinema precisa renovar a compreensão do seu campo de pesquisa com conceitos e métodos mais condizentes aos novos fenômenos e as mais recentes transformações ensejadas pela linguagem e pela tecnologia audiovisual. Recentemente traduzido para o português - e lançado pela coleção de cinema da SESC Edições - o livro de Thomas Elsaesser compartilha o teor desses impasses para vislumbrar caminhos originais e horizontes possiveis às várias revisões críticas que estão em voga. Em uma primeira sintese, o autor alemão enfatiza a necessidade de alterarmos nossa compreensão da história e da linguagem cinematográfica assim como mergulha com vigor nos sinuosos percursos que singularizam as pesquisas históricas desse emergente paradigma arqueológico.

Ao longo dos capítulos e dos ensaios do livro, percebe-se três campos que se entrecruzam e, quando combinados, ofertam uma potente metodologia arqueológica para propiciar uma revisão dos estudos de cinema. O primeiro aspecto é historiográfico, no qual Elsaesser defende uma radical descontinuidade da história do cinema. Dessa forma, o digital pode ser melhor compreendido se for buscar suas afinidades eletivas, por exemplo, no chamado cinema de atrações, anterior à consolidação da narrativa clássica. 0 segundo viés é uma ênfase necessariamente tecnológica e, tal como fênix, o cinema reinventa-se e renasce de acordo com as novas combinações tecnológicas que engendra. Por fim, Elsaesser realça uma "poética da obsolescência", pela qual tanto artistas como pesquisadores podem recuperar formatos e tecnologias cinematográficas de um passado remoto para melhor intervir no debate sobre o cinema contemporâneo.

\section{O anacronismo e outros fundamentos da arqueologia do cinema}

Embora seja um livro de compilação de diversos ensaios de Elsaesser ao longo da sua carreira, essa obra acerta ao enfatizar a agenda e o temário dos atuais debates. Questões sobre a definição de cinema, os diálogos entre a arqueologia e a história do cinema - tal como está já no título -, a centralidade e os problemas que surgem das teorias do dispositivo ganham, finalmente, a devida profundidade e a centralidade que reivindicam. Certamente, a principal contribuição desse livro está na forma como essas questões são organizadas e dispostas ao leitor. Trata-se, portanto, mais de um efervescente guia do debate contemporâneos do que de proposições teóricas, ou uma pesquisa de arqueologia da mídia no cinema, de forma empírica e minuciosa.

Anacronismo, história do presente e dialética do olhar seriam - ainda que indiretamente inspiradas em Walter Benjamin e Michel Foucault - algumas das bases do que Elsaesser denomina como a sua arqueologia da mídia. Por esse recorte, Elsaesser se refere à história do cinema totalmente vinculada ao seu momento atual; ou seja, a convergência digital transforma-se tanto em um tema a ser investigado pelo pesquisador alemão, quanto em um prisma para revisar metodologicamente os preceitos do cinema, sua história e sua teoria.

Em outras palavras, é por meio de um contexto amplamente contaminado pela tecnologia digital que a arqueologia das mídias, no cinema, atualiza-se; e revela-se uma efetiva questão presente, dinâmica, inspiradora. São variados - polimorfos e polissêmicos - os impactos da chamada revolução digital. Diante da nova episteme que instaura, o digital permite, para Elsaesser, rever o chamado primeiro cinema, as suas inovações e descontinuidades tecnológicas, a crise da narrativa e, o mais importante, instaura uma outra camada da temporalidade cinematográfica, pela qual o arquivo e o passado reconfiguram-se de 
forma que ultrapassam questões clássicas da teoria cinematográfica, como o indice e o dispositivo as quais revelar-se-iam insuficientes para responder a inflamável versatilidade instaurada pela guinada digital. Ao invés, portanto, de apostar na morte e em um melancólico luto sobre o cinema, Elsaesser busca, pelo digital, inspirar-se em uma série de debates que iluminam facetas camaleônicas do fenômeno cinematográfico, pelas quais suas reinvenções, seus renascimentos e suas novas configurações combinam genuinos traços históricos com outros futuros potentes.

No capítulo inicial, Elsaesser aborda a revisão do chamado "primeiro cinema" como o instante que realmente instaura uma perturbação nos estudos audiovisuais e cinematográficos. Ao invés de ser concentrado em narrativas, estilos e gêneros, o cinema de atrações busca uma atualidade a partir do olhar, do corpo, das formas tecnológicas que propunham experiências audiovisuais únicas ao espectador. Elsaesser constata, portanto, como a maioria das suas (do autor) formulações históricas e teóricas do cinema ocorreram privilegiando a linearidade. Classifica-se essa linguagem passando ora por períodos bem definidos e consolidados - como o pré-cinema, o cinema narrativo, o moderno e o contemporâneo - ora por recortes regionais e autorais que seguem afins a essa linha histórica. Comumente, as pesquisas sobre história do cinema também tendem a abordar autores canônicos, estilos, gêneros e grupos de filmes que são tecidos, de forma recorrente, por linhas retas - e muitas vezes teleológicas; ou seja, com poucas chances de compreensão das descontinuidades e dos inúmeros desvios de percursos históricos protagonizados pelo cinema. Nas suas principais concepções teóricas presentes atualmente, que perpassam as pesquisas de afeto, a análise filmica, as teorias cognitivas e o impacto dos estudos culturais no cinema, tende-se a ter um pressuposto histórico causal, pelo qual o cinema é compreendido como um fenômeno histórico contínuo.
A fina percepção de Elsaesser - e de muitos pesquisadores, e mesmo cineastas, da sua geração vinculados a universidades norte-americanas - é de alinhavar afinidades entre o primeiro cinema, o cinema de vanguarda dos anos sessenta, o cinema chamado pós-clássico e vários aspectos das experimentações que recentemente vêm ocorrendo dentro do cinema digital. Em detrimento da centralidade da narrativa - e da metodologia da análise filmica - esse conjunto disperso de momentos e configurações tecnológicas priorizam a experiência visual e apenas em algumas especificas ocasiões históricas possuem a centralidade da perspectiva pictórica e fotográfica como seus pilares estéticos. Mesmo aspectos como o voyeurismo, o fetichismo e o prazer visual - que são pilares da teoria cinematográfica dos anos setenta inspiradas em Laura Mulvey - revelam-se claudicantes quando precisam lidar com efeitos pós-cinemáticos, experiências em 3D e formas de narrativas audiovisuais próximas ao videogame.

O impacto das pesquisas com o primeiro cinema permitiu abordar a história filmica com certa distância diante do modelo canônico do cinema de autor. Ao contrário, esse grupo de trabalhos acadêmicos ${ }^{2}$ instigou práticas artísticas e pesquisas que busquem quebras epistêmicas, análises de formas simbólicas ou, ainda, distintos modos de olhar para realizações normativas. Por esse viés, realça-se similaridades e diálogos históricos, mesmo tecnológicos, entre diferentes mídias, suas singularidades, suas especificidades, mas também suas formas de disseminação. Em uma palavra, o fenômeno audiovisual deixa de ser estanque, pétreo e naturalizado. Ela camufla-se, veste-se, em outra metáfora possivel, com diferentes peles, quando, por exemplo, ocorre no vídeo, acontece nas mudanças de bitola da película, nos formatos 3D, cuja história Elsaesser bem analisa em um dos seus capitulos com maior consistência e documentação histórica.

No campo de pesquisa e análise do cinema de atrações, portanto, ocorreu uma inaugural e importante perturbação epistêmica. Também

\footnotetext{
2 Para uma compreensão do impacto dessas pesquisas sobre o primeiro cinema, é importante ver os trabalhos de Charles Musser, Tom Gunning, André Gaudreault e Mirian Hansen.
} 
se destaca nesse grupo de estudos que veio dos anos oitenta - e bastante influenciado pelo cinema estrutural - uma ênfase no espectador, como ente central no qual deságua o cerne da experiência audiovisual. ${ }^{3}$ Essa experiência, por tal viés não linear, tampouco é unívoca, mas mutável, dinâmica, e precisa ter suas nuances e sutilezas captadas pelo observador da história audiovisual. Se a arqueologia da mídia agrega fundamentos e lições, um deles talvez seja o de respeitar a inevitável distância do passado em relação a nossa perspectiva presente e fazer, como afirma o próprio Elsaesser, da alteridade uma das bases dessa metodologia.

Nesse sentido, a arqueologia das mídias - e, por conseguinte, do cinema - aglutina uma ampla gama de temporalidades. Logo na sua introdução, por exemplo, Elsaesser enfatiza como haveria, primeiramente, um tipo de arqueologia retrospectiva, que visa reconstruir obras, formas, e estilos passados, cujos arquivos encontram-se desaparecidos, dispersos ou simplesmente foram negligenciados. Um segundo aspecto da arqueologia seria prospectivo, e nessa seara a metodologia arqueológica faria, de forma curiosa, um vislumbre de futuros possiveis; ou, por outro prisma, permitiria uma historicidade de futuros imaginados.

Na radicalização da recusa de um essencialismo cinematográfico, Elsaesser, alcança a uma frase deveras polêmica: o cinema é uma invenção sem origens precisas. O primeiro motivo dessa sentença é calcado em uma complexa confluência tecnológica. O cinema seria uma sintese de diversas invenções que parecem mais remotas - como por exemplo o telégrafo - e não estaria limitado a uma decorrência da fotografia nem da imagem em movimento. Em uma camada mais profunda, no entanto, Elsaesser remete a uma importante distinção entre a arqueologia e a genealogia. Para ele, a genealogia esforça-se para elaborar uma linha contínua entre o presente e o passado; enquanto a arqueologia respeitaria a descontinuidade, a força dos fragmentos, e permite que o presente seja uma forma de acessar o passado. Um arqueólogo das mídias, portanto, teria uma inclinação mais propensa para jogar luzes naquilo que foi suprimido, em aspectos faltantes, incompletos e abandonados.

Embora seja válida e instigante, essa diferença entre arqueologia e genealogia pode apresentar alguns problemas. No seu seminal ensaio sobre Nietzsche e a genealogia da história, Foucault (2014) usa o termo de genealogia muito próximo da concepção que Elsaesser faz de arqueologia. Mesmo quando haveria continuidade, essa seria permeada por irrupções, abandonos e retomadas, como se propiciasse, outros retornos, outras diferenças e potências distintas a cada nova configuração. Na pesquisa histórica de Foucault, os dispositivos seriam redes de discursos - muitas vezes institucionais, que engendrariam novas formas históricas de concepções e experimentações dos sujeitos. O instante da irrupção do evento genealógico, portanto, é essencialmente arqueológico; ou seja, ele é indefinido, aberto, poroso, sensivel, suscetivel a transformações. O teor da leitura genealógica, por outro lado, cria fios históricos que culminam no tempo presente. Em jargões de narrativa e montagem cinematográfica, a genealogia seria um flashback-forward; enquanto a arqueologia implementaria um flashback que não necessariamente criaria uma explicação narrativa para a situação presente - ela apenas instaura uma outra temporalidade histórica.

\section{Para além do dispositivo: teoria, tecnologia, narrativas}

No seu segundo capítulo, Elsaesser aborda as minúcias da aventura arqueológica dentro dos estudos de cinema. Curioso e provocativamente, o problema desse capítulo concentra-se na revisão do conceito de dispositivo, e em um aprofundamento crítico do que Elsaesser denomina como a teoria do aparato e do cinema de arte. Ao partir do pressuposto de que as mudanças contemporâneas da convergência digital são voláteis, imprevisiveis, e mesmo contraditórias,

3 Ver (HANSEN, 1994), um dos principais trabalhos sobre a formação do espectador durante o período do cinema mudo. 
Elsaesser dedica-se a tratar o dispositivo também como um aspecto dinâmico e mutável. Nesse diapasão, ele sugere três campos de revisão, de forma a propiciar musculatura e corpo empírico a essas novas formas de investigar o primeiro cinema. A primeira revisão é propriamente a da arqueologia da mídia, que torna perecivel aspectos tidos como monolíticos do dispositivo, tais como a tela, o quadro, a projeção, a opacidade e a transparência. O dispositivo também é um ente histórico, e seria preciso enxergá-lo nas suas metamorfoses, sejam elas epistêmicas, tecnológicas ou, ainda, sensíveis.

O segundo campo de revisão seria teórico e conceitual. Elsaesser, por esse viés, sugere uma nova leitura de autores clássicos da teoria do cinema - como André Bazin, Siegfried Kracauer, Jean Epstein e Bela Bálazs - pelos quais haveria abordagens compreensivas e mais versáteis do fenômeno da chamada sétima arte. Essa revisão também deveria ser acompanhada de um contraste com autores mais recentes, ou contemporâneos - como Friedrich Kittler, Lev Manovich, David Bolter e Mary Ann Doane - que permitem revisar conceitualmente o cinema a partir de uma problemática instaurada pela convergência digital.

O terceiro campo de revisão é perpassado por um prisma tecnológico, pelo qual as técnicas cinematográficas também grifam uma peculiar historicidade, a qual não deve ser negligenciada. Essas técnicas configuram novas formas de visualização, de sensibilização do espectador e de fruição da experiência audiovisual. Um teórico como Francesco Casseti, por exemplo, vai cunhar a expressão da "explosão das telas" para repensar as relações entre tecnologia e espectador no âmbito da teoria e da história audiovisual (CASSETI, 2015). Por esse campo de revisão, portanto, a arqueologia da mídia afasta-se totalmente de uma certa tecnofobia que ainda tende a assolar os estudos de cinema, em particular, e as ciências humanas, de forma mais geral. Pelo contrário, a arqueologia da mídia revela-se aguda e adequada a essas alterações tecnológicas intimamente entrelaçadas a profundas transformações na forma de realização e recepção de fenômenos audiovisuais. Do advento do som à chegada de novas bitolas; da televisão à explosão digital, vem ocorrendo inúmeras e sensiveis mutações. Na sua ampla agenda temática - e de possibilidades de pesquisa, a arqueologia das mídias enfatiza essas irrupções pelas quais as mudanças tecnológicas dinamizam outras perturbações.

O caso da narrativa é exemplar. Sempre preocupado em estabelecer uma arqueologia da mídia digital, Elsaesser pergunta-se no sétimo capítulo, como fica o problema da narrativa no contexto digital. Por ser construida a partir de tecnologias algoritmicas, reversiveis e não lineares, o digital impele a uma narrativa a ser transformada, e permeada por questões referentes ao tempo, aos sujeitos e aos espaços que são conjugados em uma dinâmica de aqui e agora. Alinhado a Elsaesser, Cassetti chamará esse paradigma de hipertopia, uma forma de espacialidade nova, implementada pelo digital, na qual o espaço alcança os espectadores, enquanto esses locomovem-se livremente.

$\mathrm{O}$ digital, portanto, instaura uma radical mudança. Mais distante da literatura e das letras, a contemporânea narrativa digital estabelece uma interface entre o acesso a dados e um usuário. Está mais próxima das interfaces de games do que de leituras semióticas. Ademais, o digital engendra ruidos de uma linguagem e de uma narrativa, a qual é predominantemente verbal. Ele acaba submetendo-se a um paradigma informacional, que tem a programação algoritmica como um dos seus principais fundamentos. Plataformas como o Youtube, Google e outras aplicativos digitais mais contemporâneos apenas aguçam as interfaces entre a linguagem do verbo e a linguagem da programação. Por essa arqueologia, o digital tende a ser compreendido como uma metáfora cultural, na qual seu processo atualiza antigas narrativas e tecnologias com a abertura para novas experiências:

É em relação a esses efeitos-sujeito que o argumento sobre a diferença fundamental, ou a convergência provável, entre narrativas e games pode ter de ser repensado. Por exemplo, em algumas das chamadas narrativas 
interativas, o principio dos games de acumular pontos é transformado em ficção numa repetição em série de ações, com o maior placar de pontos dando acesso a outros níveis da história, simulando maior complexidade narrativa (ELSAESSER, 2018, p. 214).

Não restrita apenas ao cinema, portanto, a guinada digital é em si uma nova forma de coligar linguagens, tecnologias e espectadores. Seus principais desdobramentos seriam sintomas afins às inquietações que guiam a arqueologia da mídia, e a interface entre a programação e o cinema contemporâneo. Busca-se, por esse viés, os efeitos dos programas e softwares, utilizados, por exemplo, dentro da animação, dos cenários virtuais, da constante mescla entre "live cinema" - o cinema gravado ao vivo - com o audiovisual animado por algoritmos. No seu The Virtual Life of Film, David Rodowick persiste em procurar uma certa genealogia da imagem digital que não repousa nem no traço e tampouco na fotografia. Para esse teórico, o digital estaria mais próximo, em termos ontológicos, de uma linguagem da animação, na qual o índice, a captação e mesmo os efeitos de realidade não seriam os principais protagonistas (RODOWICK, 2007). Atenta à criatividade visual, a animação seria um paradigma não linear, autorreferencial e facilmente manipulável na linguagem cara à programação.

Esse amplo panorama permitido pelo conceito de dispositivo incide, consequentemente, no cerne da questão da experiência. Se há alteração no dispositivo, o espectador também é outro. Por esse recorte, a arqueologia da mídia é uma das metodologias mais generosas para compreender o anacronismo inerente ao espectador cinematográfico e audiovisual. O cinema de atrações foi fundamental para inserir esse viés dentro dos estudos de cinema. Na sua vertente, o espectador do primeiro cinema é um tipo histórico único, que pode até possuir algumas afinidades com o espectador contemporâneo de Graphics Interchange Formats (GIFs), memes, e gags que circulam pelas redes sociais. Mas estamos falando de formatos e experiências históricas ou mesmo de sujeitos-espectadores completamente diferentes.
O espectador de televisão não é o mesmo do individuo que acompanha um Western em 70mm. O espectador de séries de TV da Netflix tampouco equipara-se à massa de filmes mudos exibidos em vaudevilles e que dialogavam profundamente com o melodrama e atrações circenses. Se muda o espetáculo, altera-se, consequentemente, a sua forma de fruição. Quando levada às últimas consequências, a arqueologia da mídia também se desdobra em uma outra concepção metodológica, já que a análise filmica, demasiadamente concentrada na narrativa, não seria capaz de captar as mudanças de padrões tecnológicos, de outras configurações de dispositivo e tampouco das novas formas de efetivação da experiência cinematográfica. A arqueologia da midia, portanto, propiciaria uma profunda ruptura epistemológica nas convenções mais canônicas dos estudos de cinema. De certa forma ela aponta para desafios incontornáveis para a análise filmica, afastando-se dessa tradição de estudos literários, calcados na semiótica, no estruturalismo, e aproximando-se das mais recentes concepções da assim chamada materialidade da comunicação. Movente, o cinema transfigura-se, acontece nova e diferentemente a cada uma das suas metamorfoses.

\section{Poéticas da obsolescência}

De certa forma, a arqueologia das mídias possui um íntimo diálogo com obras experimentais da vanguarda norte-americana, como o cinema estrutural, e com um conjunto de obras audiovisuais contemporâneas que tendem a circular mais por museus e galerias do que por salas de cinema. Cineastas como Harun Farocki, Tacita Dean e Ken Jacobs, entre outros, são algumas das esparsas referências cinematográficas que pontilham os exemplos de Thomas Elsaesser nesse livro. Atento a essas especificidades, no entanto, Elsaesser é certeiro ao vislumbrar uma poética da obsolescência que marca essas obras em uma lenta (e importante) relutância em acatar passivamente o ritmo imposto das mudanças e dos padrões tecnológicos à linguagem cinematográfica. Evidencia-se, primeiramente, uma certa nostalgia da película, que, marca parte da 
obra de Tacita Dean. Essa nostalgia repercutiria em muitos filmes e obras que tendem a ter uma certa relação "vintage" com o passado cinematográfico e outras configurações tecnológicas, mesmo as contemporâneas, em edulcorar um momento já tido como passado.

Se há um primado da arqueologia da mídia e de uma arqueologia do cinema, essa ocorre permeada por uma densa e ampla gama temporal. Siegfried Zielenski, que é um dos pioneiros desse campo de estudo, aborda técnicas visuais e concepções tecnológicas anteriores ao "surgimento" do cinema - e que, muitas vezes, sequer possuem intersecções com a chamada sétima arte. Zielenski chega a fazer comparações entre a arqueologia da mídia e o estudo de fósseis (ZIELENSKI, 2008). Jussi Parikka, seguindo a mesma esteira, vai propor uma "geologia da mídia". Seja com Zielenski, Parikka, ou com Elsaesser, a arqueologia da mídia torna-se uma agenda de pesquisa que busca rastros, descontinuidades, desaparecimentos e ressurgimentos. Uma temporalidade, por assim dizer, que pressupõe vetores rizomáticos e agenciamentos de espaços e temporalidades distantes de uma configuração linear da história, e que pressupõe forças de supressão, mas também não caem facilmente na retórica de entender o passado como uma antípoda do "progresso" ou mesmo do futuro.

No contraponto, portanto, à nostalgia inerente a certo recorte da arqueologia da mídia, surgem obras e reflexões como uma certa maneira de resistência a essa obsolescência. Por que descartar formas estéticas, técnicas e configurações tecnológicas do passado? Como expressão intimamente industrial e econômica, o cinema também teria uma constante indução a descartar formatos, bitolas, formas de produção. Seria uma arte que constantemente descarta seus suportes, e suas obras. Boa parte daqueles artistas e cineastas trazem o passado como um gesto de irrupção e atualização do presente, mas também como uma forma de negar uma história progressista do cinema. Farocki, por exemplo, volta-se, em alguns casos, para os irmãos Lumière para pensar as formas contemporâneas das câmeras de vigilância.
Jacobs trabalha somente com filmes de arquivo e adentra com vigor no periodo de espectadores prévios à narrativa consolidada por D. W. Griffith.

O gesto arqueológico, portanto, teria tanto uma primazia poética quanto seria uma forma de complexificar as vias de mão única que caracterizam o acelerado processo caro à história cinematográfica. O que era descartado, torna-se atual. O que era lixo da história, ganha, novamente, uma outra vitrine. A poética da obsolescência, conforme aponta Elsaesser, também pode ser uma forma da linguagem audiovisual dialogar com os recentes apontamentos do realismo especulativo, e de uma ontologia orientada aos objetos. Nesse sentido, a arqueologia das mídias e do cinema inauguraria uma nova agenda para o pensamento, a teoria, a história e as pesquisas de cinema a partir da perspectiva do objeto e do aparato.

Falecido no final de 2019, Elsaesser nos deixou uma agenda bem organizada, com questões pertinentes aos estudos de audiovisual, sem se eximir de cotejá-los com aproximações caras à filosofia, à história e ao pensamento crítico da tecnologia. Cabe aos seus leitores, e à geração que o sucede, tentar responder a essa agenda com a mesma paixão, minúcia e seriedade que ele transmitiu nos seus textos, suas aulas, palestras e tantas intervenções públicas.

\section{Referências}

CASSETI, Francesco. The Lumière Galaxy: seven keywords for the cinema to come. Nova York: Columbia University Press, 2015. https://doi.org/10.7312/colum$\mathrm{bia} / 9780231172431.001 .0001$

ELSAESSER, Thomas. Film History as Media Archeology: tracking digital cinema. Amsterdam: Amsterdam University Press, 2016. https://doi.org/10.2307/j. ctt1zxskjv

ELSAESSER, Thomas. Cinema como arqueologia das midias. São Paulo: SESC Edições, 2018.

FOUCAULT, Michel: Microfísica do poder. Rio de Janeiro: Editora Paz e Terra, 2014.

GUNNING, Tom. D. W. Griffith and the origins of the American narrative film: the early years at biograph. Chicago: University of Illinois Press, 1993.

HANSEN, Mirian. Babel and Babylon: spectatorship in American silent film. Boston: Harvard University Press, 1994 
MULVEY, Laura. Visual and other Pleasures. Londres:

Palgrave Macmillan, 2009.

PARIKKA, Jussi. What is Media Archeology? Cambridge: Polity Press, 2012.

RODOWICK, David. The Virtual Life of Film. Boston: Harvard University Press, 2007.

https://doi.org/10.4159/9780674042834

ZIELIENSKI, Siegfried. Arqueologia da Midia: busca do tempo remoto do ver e do ouvir. São Paulo: Annablume, 2008

\section{Pablo Gonçalo}

Doutor em Comunicação pela Universidade Federal do Rio de Janeiro (UFRJ), no Rio de Janeiro, RJ, Brasil. Pós-doutorado EM Comunicação pela Universidade de São Paulo (USP), em São Paulo, SP, Brasil. Professor da Universidade de Brasilia (UnB), em Brasilia, DF, Brasil.

\section{Endereço para correspondência}

Universidade de Brasília, Campus Darcy Ribeiro

Faculdade de Comunicação

Asa Norte, 85867900

Brasilia, DF, Brasil. 